CHAPTER 5

\title{
Homeric Framings
}

The feat of extricating a particular element from a pattern shows intelligence at work within perception itself. Quite in general, intelligence is often the ability to wrest a hidden feature or disguised relation from an averse context. It is an ability that can lead to important discoveries. At the same time, the resistance of the context to such an operation raises a peculiar problem. After all, there is good sense in the warning that "one must never take things out of context." They may be falsified, distorted, and even destroyed by the isolation. At the very least they may be changed.

-Rudolph Arnheim, Visual Thinking

If telling the epic story may be seen in terms of translational movement, then the act of narration and its syntactic articulation not only involve movement but also a knowledge of where to move. The very selection of a path implies orientation and a sense of direction, and the act of movement typically presupposes that one has found one's bearings. This aspect of epic narrative has been well described and documented in various ways. For example, in his discussion of Homeric catalogic style, Krischer has pointed out a pervasive tendency to state the general character of a scene or sequence of scenes, by way of orientation, and only then to state the particulars. ${ }^{1}$

A simple but instructive example of this phenomenon is the beginning of battle in the fourth book of the Iliad: a general picture is presented of the two opposed armies, the din of battle, the cries of victors and vanquished, and blood streaming over the earth (Il. 4.446-56). Only then do we hear that Antilokhos was "the first" to kill a Trojan warrior (457), a statement

${ }^{1}$ Krischer I97I: I32. Krischer's demonstration involves such topics as the organization of aristeiai (traditional description of a hero's finest hour in battle), and a reassessment of Zielinski's Law (see Zielinski I 899-I90I), which, as Krischer points out, is based on moments of branching (Verzweigung) of two action strings-particulars that are preceded by a general, orienting statement. 
that sounds odd in the light of the mayhem that has already been described. ${ }^{2}$ It becomes understandable, however, when one realizes that the preceding description was an orienting preview, a look ahead along the narrative track, rather than a narrative, referential statement in its own right.

A natural consequence of speaking about the speech process in spatial terms is that orientation in speech may be seen, quite literally, in terms of awareness of one's surroundings. Chafe, whose ideas on consciousness and speech were introduced in Chapter 3 , notes that the human mind needs a general sense of time and place in order to "be in" a given situation. ${ }^{3} \mathrm{~A}$ moment of focal vision, for example, needs a certain amount of background awareness in order to be meaningful and enlightening, and in general terms, any piece of active information or moment of consciousness requires a certain amount of information, of which one is half-conscious, to serve as its background. ${ }^{4}$

When a consciousness is engaged in remembering and imagining, as in the case of most narrators and their audiences, actual vision turns into visualization, but the need for orientation remains. One's surroundings and relative position on the path of speech will be determined vis-à-vis a given scene, a mental picture. Such a scene is too substantial to be grasped in its entirety in one focus of consciousness, however, and has to be broken down into its constitutive parts during its mental scanning, while it is being verbalized into a series of speech units. This process benefits, in many cases, from a global, orienting unit, which precedes the description of the scene and provides context for it. Consider, for example, what one of Chafe's subjects in the Pear Film project does in the verbalization of a scene: ${ }^{5}$

a. [I.IS] A - nd [.I] then a boy comes by,

b. [.I] on a bicycle,

c. the man is in the tree,

d. [.9] and the boy gets off the bicycle,

e. and . looks at the man,

2 Krischer 1971: I 34; see also Latacz I977: 83. See also the remarks on $\pi \rho \hat{\omega} \tau$ to 5 as a processual, rather than referential sign in Chapter 4 above.

3 Chafe I980: 26-49; 1987: 42-45; 1990: 93-96; 1994: 30, I28-29.

4 Chafe speaks of "peripheral consciousness" here and "semi-active" information (1987:25, 28-3 I; 1994: 53, 72). More on "active" and "semi-active" (as well as "inactive") later on in this chapter.

5 See Chafe, ed. I980: 307; Chafe 1980: 27 . On orientation in storytelling see also Labov 1972: $363-65$. 
f. and then [.9] uh looks at the bushels,

g. and he .. starts to just take a few,

h. and then he decides to take the whole bushel.

This speaker is visualizing a scene in his head: in units $a-c$, he orients himself by giving the general character of the scene, which in this case consists of the participants and their relative locations. Once this background has been established as context and direction for the narrative, the speaker can proceed by giving the little story of which the scene consists. As a Homeric speaker would do with dé, he marks the successive steps with the continuative particle "and." 6

A unit verbalized after an orienting statement may be said to be added to it, which leads us back to the philological notion of adding style discussed in Chapter 3. Just as in the case of parataxis as movement, I propose to replace the stylistic concepts of adding style or appositional style with one that emphasizes agency. In terms that are less metaphorical than they may seem, we might speak then of a close-u $p$ : the speaker stands still for a moment on the path of speech to look more closely at the scene, or the speaker focuses on how the scene came about, explaining it and thus providing a basis for what is next in the story. This activity finds its expression in loose, fragmented syntax, the addition of speech units of any kind (from nouns or nounepithet phrases to participial or prepositional phrases to whole clauses). Such loose syntactic addition, however, is very different from mere random cumulation, as we shall see. The addition of a detail or piece of explanation crucially presupposes a context in which the detail falls into place. And this context more often than not has been set up explicitly in order to accommodate the detail verbalized in the addition.

Rather than being unplanned, then, added units in the adding style are at the heart of strategies that involve planning and looking ahead. This is especially the case when the unit(s) serving as background (I shall speak of "starting point") is (are) a preliminary, global preview of an event to be described more fully in the narrative. Such a preview serves as a guidepost indicating the course and direction to be taken on the path of speech. "Orientation" is the term that I have been using; another term, pertaining less to movement than to vision, is "framing." This word is often used in linguistics and cognitive science in ways that are so professionalized that

6 See above, Chapters 3 and 4 .

7 "Frame" is a key term in the discussion of knowledge representation as conducted since the 
even the metaphor behind it has been lost. My use of the term below will be quite literal and graphic: I define it as the demarcation of a frame limiting one's field of vision for the next moments or speech units, the area within which addition of detail can meaningfully take place. Orientation and framing have a wide range of syntactic manifestations in Homeric discourse, from thematic noun phrases staging the participants in a given event to the proleptic mentioning of events before they are due in chronological order. But whatever their nature, all these grammatical elements testify to the general movement of Homeric discourse, syntactically or suprasyntactically, from the global to the specific, and from the framing to the framed.

\section{Close-Up and Addition}

In the discussion of mén at the end of the previous chapter, we saw that progression and continuation may require a looking ahead in the flow of discourse: a speaker may verbalize a clause not so much as a statement in its own right as to provide a stepping-stone for statements to be verbalized shortly thereafter. In the same way, an adding unit that provides a second, closer look at a given scene may be prepared and staged by a preceding unit that serves as its frame (in visual terms) or starting point (in terms of movement). The relation between framing discourse on the one hand and detail within the frame on the other appears to be quite fundamental for Homeric discourse. In what follows I shall discuss some of the syntactic aspects and possibilities of framing and close-up, keeping an eye open for the same or similar phenomena on the suprasyntactic levels of the organization and flow of Homeric narrative. The following may serve as typical examples of moments of addition in which a close-up is verbalized:

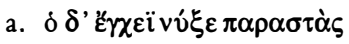
and with the spear he hit [him] from nearby,
b. $\gamma v \alpha \theta \mu$ òv $\delta \varepsilon \xi$ ıा $\varepsilon \rho o ́ v$, on the right jaw.

$$
\text { (Il. I6.404-5) }
$$

mid-I970s within the context of cognitive science and artificial intelligence (e.g., Winograd I975), in which the word denotes "cluster of knowledge," "interconnected network of information," or the like. Closely related concepts are goals, plans, and scripts (culturally determined mental scenarios for certain action sequences directed at performing a given task). See Schank and Abelson 1977. The application of these concepts to Homer (Miller 1987; Minchin 1992) is anticipated in the work of Nagler (1974). 


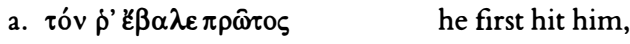

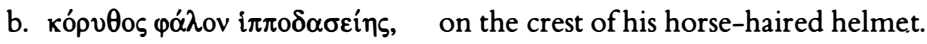

The b-units are, in syntactic terms, additions to the a-units. In terms of the underlying cognitive activity that propels verbalization and syntax, the speaker uses the b-units to focus on a detail selected from what had been visualized a moment before. The b-units narrow down the field of vision and zoom in on the scene, which is itself already a selection. The more detailed second shot is entirely dependent for its meaning on the more global first one, and so is its verbalization. Syntactically, the adding unit has no independent status; it leans on the preceding one which serves as its frame.

The notion of syntactic dependence and apposition might seem to imply that the adding unit is less important than the previous unit: an appendix or optional afterthought to something already complete. But whatever the value of this characterization may be for other discourses, it surely does not apply to Homer. When a unit is added, a detail within a frame has been singled out for verbalization. Nothing compels us to say that the detail is any less important than the frame, and in fact the detail may be the very reason why the frame has been set up at all. We begin to see, then, that between addition and framing a reciprocal relation may exist: if a given unit $\mathrm{y}$ is adding to the preceding unit $\mathrm{x}$, then the function of unit $\mathrm{x}$, conversely, may be the framing of unit $y$.

Units uttered within a frame, considered not in the dimension of vision but as a matter of performance time, can be seen as expansions of the framing unit. The way in which framing units provide context for units to come, in fact, is a major aspect of the aesthetics of Homeric discourse that emerges when the unperiodic strung-on style is studied as a phenomenon in its own right, rather than with reference to periodic style. In a recent article, Joseph Russo has discussed the pervasive Homeric tendency toward repetition and fullness and has characterized it as "Item Plus," the "master trope of traditional epic verse-making." 8 According to this principle, a given basic idea can be supplemented by material that is either an appositional, an explanatory, or a metonymic extension, according to whether it rephrases or widens the basic idea, or links it to what follows. This phenomenon is indeed pervasive in Homeric discourse. In Chapter 8 we shall deal with the implications of the expansion aesthetic for the way in which

${ }^{8}$ Russo I994: 374. 
meter and formulas are deployed; in the present chapter we are concerned with how expansion involves the resources of ordinary language.

The detail added to a preceding framing unit need not be visual. Often the mentioning of a name, the verbalization of the theme of a hero, activates concepts and facts associated with this hero. The peripheral notions are added to the name appositionally in the form of epithets, patronymics, or other qualifications. Accumulation of such details takes time and is thus the usual strategy in the full, catalogic introduction of heroes, as in the following example: ${ }^{9}$

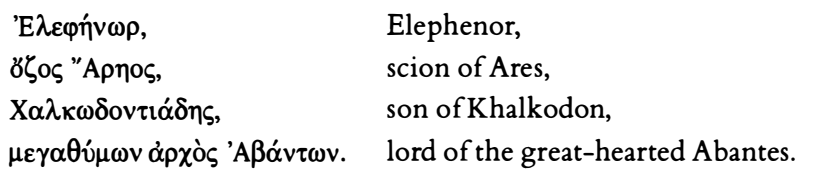

(Il. $2.540-4 \mathrm{I})$

Whenever one of the qualifications associated with a name involves the relation between two items (e.g., the bearer of the name and someone else or his place of birth) and accordingly needs a verb, the consequence will be an appositional (digressive) relative clause. ${ }^{10}$ Such appositive relative clauses are the usual introduction to the biography of the hero slain in the battle, on which see below. The relative clause may occur at any moment during the list of qualifications and is not bound to the slot immediately following the name. Consider, for example, the first appearance of Kalkhas the seer in the Iliad:

\begin{tabular}{|c|c|}
\hline 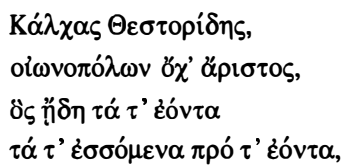 & $\begin{array}{l}\text { Kalkhas son of Thestor, } \\
\text { of the bird-watchers by far the best, } \\
\text { who saw what is, } \\
\text { what will be and what came before. }\end{array}$ \\
\hline
\end{tabular}

(Il. I.69-70)

Very often, the situation is reversed and the name itself is added to what precedes, rather than specifying the theme to which subsequent additions

9 The same sequence, except for the insertion of $\measuredangle \zeta \circ \varsigma$ "Ap 4.463-64, and Elephenor is not mentioned again in the Iliad. Has the second mention been triggered by the presence of the first? See Beye 1964: 363 on the influence of the Catalogue on the earlier stages of the Iliad battle and Hainsworth 1976 on clustering as a feature of Homeric discourse in general, a phenomenon that is amenable to cognitive analysis.

${ }^{10}$ Appositive relatives are hardly subordinate clauses (Lehmann I984: 270-72), and the dividing line in Homer between relatives and anaphoric pronouns is sometimes hard to draw. 
conform. Typically, what precedes the added name is a clause consisting minimally of an anaphoric pronoun in the nominative case and a verb; the pronoun is most often marked by dé as a moment of continuation in the narrative (ho dé 'and he'). Sometimes the addition of the name takes place within the confines of a recognizable speech unit; ${ }^{11}$

ó $\delta \varepsilon$ oi $\sigma \chi \varepsilon \delta$ òv $\hat{\eta} \lambda \theta \varepsilon v$ 'A $\underline{\chi} \imath \lambda \lambda \varepsilon \dot{v} s$. and he, Achilles came close to him.

But more frequently, the name constitutes a speech unit on its own, and epithets are often involved. Consider, for example: ${ }^{12}$

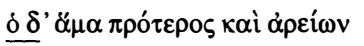

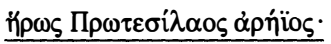

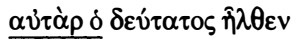

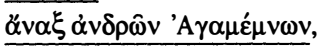

but he [was] both older and braver,

hero Protesilaos the warrior.

(Il. 2.707-8)

but he, he came last,

lord of men Agamemnon.

Such added names are in agreement with a pronoun in the nominative case in the preceding clause, and thus the pronoun and the name denote one and the same person. In other cases the pronoun is in an oblique case and denotes a character other than the character to whom the name belongs. These cases include the well-known answering formulas discussed by Parry in his study of the noun-epithet formula in Homer. ${ }^{13}$ Rather than considering them predicate formulas followed by subject formulas I treat them here as two stylized intonation units: a separate naming unit added to a preceding clause:

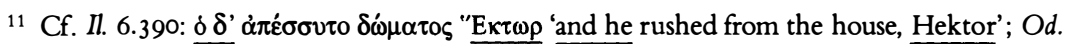

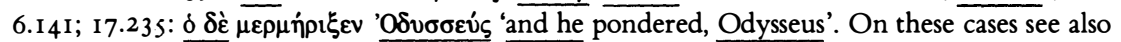
Chapter 8 below. Cases in which a name-epithet formula is added to a verb within the conf ines of a metrical unit include Il. 5.617, 859; 12.462; 13.823; 20.388; 21.16I; 22.330; 23.218, 779; Od. $6.117 ; 7.21 ; 13.187 ; 17.506 ; 22.81$.

12 Almost any page in Homer yields instances of this phenomenon. See, for example, $I l$. I.488-89; 2.105; 2.402; 3.8I, I 18, 328-29; 4.329, 502-3; 5.17-I 8, I 33, 449; 8.355-56; 10.148; I 5.520-2I; I6.317-I 8, 339-40, 479-80; 19.40; 20.502-3; 21.67, I62-3; Od. I.125, 319; 5.94, 354; 6.I, 4I , 224, 249; 7.I, I 39, I77, 230, 344; 8.7; I4.4I 3; I8.3II-II2; I9.I (=5I); 20.I, 242; $21.359 ; 22.1 ; 23.344 ; 24.176$.

13 Parry I971: I I-I6. 


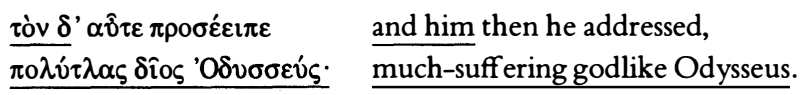

The use of a noun-epithet formula as an addition to a clause has many aspects: stylistic, poetic, and metrical. These will be discussed in Chapters 7 and 8 below. But features like style, formulas, and meter are not aesthetic features in and of themselves, or features that separate poetry from prose. Rather, they derive from the properties of ordinary language and should, accordingly, be studied from the point of view of speech before we assign poetic functions to them. Segmentation into speech units is due to cognitive factors and properties of the human mind, and the way in which those units are added to each other in the linear progression of the epic tale also has its source in the workings of the conscious mind. What then is the function of names or nouns that are added, as separate intonation units, to a preceding clause in the flow of speech?

To answer this question we have to return to the notion of topic or agent introduced in the previous chapter. Mentioning a name may evoke a set of associations (to be emphasized by an epithet, for example), but that does not exhaust the functions of names in the epic story. Names denote concepts that are likely to last longer than a single act of perception and its verbalization: instead of being a passing moment experienced on the path of speech, names often denote concepts that are active through time, in the speech flow of the performance. A hero or god who is an agent through a sequence of events is at the same time an active concept through the series of events that constitutes the representation of the epic events in speech, that is, in the consciousness of the speaker and his audience. Such a concept is not merely something experienced on the path of speech, but a companion on that path, sometimes for short distances, sometimes for longer stretches, or even all the way through.

Such longer-lasting concepts need a certain amount of management to serve their purpose in the epic story: there are always other characters on the scene with whose actions the activities of a given protagonist interact; or the concept of a protagonist may have to be reactivated in the minds of the audience. Often a mere topic switch (verbalized as ho dé 'and he') suffices to keep track of the concept of a given character and identify him with respect to others. This happens in the example given in the previous chapter, where the narrator returns to Diomedes after some time has elapsed, or rather, he reactivates the idea of this hero in his mind: 


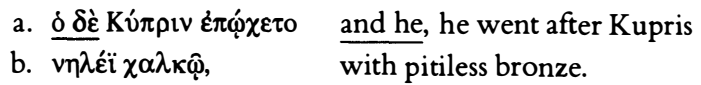

(Il. 5.330$)$

But sometimes the narrator judges that more is necessary. In the example just given, the poet could have said Tudéos huiós 'Tudeus's son' instead of nēléi khalkối 'with pitiless bronze' in unit b, loosely inserting a name that might have been redundant for some listeners but not for others. Names, then, may be used in Homeric narrative, not as subjects to any clause, but as tracking devices, reminders of who is active at a given point. And in uttering them, the speaker is not so much concerned with new information as with channeling the flow of speech and making sure that a given event is seen in the right perspective-again I stress the processual over the referential. Such additions may often seem redundant and unnecessary to us as readers, but then we are outside the flow of speech, being in a position to look back in our text and to see, in the two-dimensional, timeless space of the printed page, what was meant to be experienced along a track on which returning is impossible.

The addition of names or nouns is often called "right-dislocation" in linguistics; this infelicitous term not only introduces a two-dimensional visual opposition (left vs. right) that derives from the printed page and is of no concern to Homer (or to any other speaker for that matter), it also implies a deviation from a sentential norm, a movement of a word or phrase out of its proper place. ${ }^{14}$ Such a characterization, which is also apparent in terms like "afterthought" or "repair," 15 amounts to the ancient "strungon" verdict in modern guise. All this nomenclature describes speech in terms of writing: it starts from the ideal of an integrated sentence and treats what is most natural to speech as a deviation from this norm.

Speech occurs in time and proceeds by addition. In this process, additions are not "right-dislocations" that "repair" the previous clause; that clause is a starting point, the context set up for the proper mention of a

14 The term "right-dislocation" derives from transformational linguistics, but is also being used by functional linguists. See, for example, Givón 1984-91: 760-62; Geluykens 1994: 89. I have also used this terminology in an earlier effort dealing with these matters (Bakker I99ob: I0I I). On the complementary phenomenon of left-dislocation, see below.

${ }^{15}$ Compare also the notion of "tail" in Dik I989: I 35, 265, 358, def ined as a "final constituent which falls outside the clause proper" (358). 
name and other pieces of detail. ${ }^{16}$ Such a starting point may consist of a clause in its most simple form, the pairing of a verb with an object, and it may serve the purpose of indicating an event in a global and preliminary way, as a frame accommodating pieces of detail to be supplied shortly, or as a kind of checklist, containing items in embryonic form to be worked out later. As an example of this phenomenon, consider the following passage: ${ }^{17}$

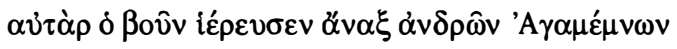

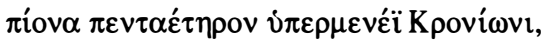

(Il. 2.402-3)

What we have here, within the reception conventions of our reading culture, are two hexameter lines in which a sentence is expressed: "But leader of men Agamemnon sacrificed a fat, five-year-old bull to the allmighty son of Kronos." In the translated sentence, the subject, direct object, and indirect object are all integrated within an overarching construction, held together by the verb "sacrificed." Such a sentence, however, would be unlikely to occur in speech, whether ordinary or special; its conglomeration of detail would be too complex to be grasped by the verbalizing consciousness as an integrated whole. An alternative is to conceive of the Greek as a short track (which is part, of course, of the ongoing narrative track), consisting of a starting point that verbalizes the event in the most general way (boûn hiéreusen 'sacrificed a bull'), to which detail is added in three installments, each being a separate intonation unit and representing a separate focus of consciousness, and one of them being the loose addition of the name of the agent in the event:

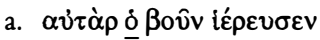
but he, he sacrificed a bull,

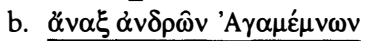

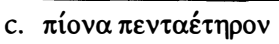
ruler of men Agamemnon,
d. نं $\pi \varepsilon \rho \mu v \varepsilon \varepsilon i ̈ ~ K \rho o v i ́ \omega v ı$,
fat, five years old,
to the all-mighty son of Kronos.

16 Notice that the notion of "starting point and added information" also figures prominently in the work of Chafe. See, for example, Chafe 1987: 36-38; 1994: 82-85. But whereas for Chafe the relation between starting point and addition pertains to the internal constituency of a clause (the starting point being the subject of the clause, in speech mostly a personal pronoun), in the argument presented here it applies to the relation between the clause as a whole and what follows it.

17 See also the analysis of Il. I. I-7 in Bakker $1997 \mathrm{~b}$. 
The nominative noun-epithet phrase in unit $b$ is not the subject of the clause, nor is the dative noun-epithet phrase in unit $d$ its indirect object. Both are additions, appositions to the clause in unit a, details filling in the picture. The nominative phrase in unit $b$ agrees with the pronoun ho in unit $\mathrm{a}$, just as the accusative phrase in unit $\mathrm{c}$ agrees with the object boun 'bull' in unit a. But whereas boun is necessary as an object, owing to the fact that "bull" is an integral part of the idea verbalized in unit a, the pronoun ho is surely not necessary as a subject. Its function is to indicate a topic switch, a shift in attention, and the reestablishment of Agamemnon as agent or protagonist after the concept of this hero has been out of focus for a few moments (2.394-40I). In the previous chapter we have discussed such switches as moments of continuation marked by the particle dé; in unit a the particle autár appears instead. This particle has an original meaning that is perhaps more specifically adversative than that of dé (whose meaning, as we saw, amounts to a weakened version of the evidential particle). ${ }^{18}$ For the purpose of marking switches and other transitions in Homeric discourse, however, the two particles are equivalent and serve as metrical alternatives for one another. In what follows I will treat them indiscriminately. ${ }^{19}$

The degree of naturalness with which nominal units can be added to a clausal core in Homeric discourse is connected with a peculiarity of the Greek verb which is obvious but often underestimated in our sentential perception of Homer and other Greek texts. The Greek verb does not need an overt nominal or pronominal subject: it expresses person and number by its own morphology and is thus more autonomous than the English verb. And if the verb is more autonomous, so are the noun phrases following it (or preceding it, as we shall see in the next section). This fact is presented as follows in one of the handbooks of comparative grammar: "The verb phatsi 'they say' does not need a subject to be plural. And it is not the apposition egó te kai sú ['both I and you'] that ensures that the verb sunomologésōmen ['let us come to agreement'] is first person plural in Plato's phrase at Thg. I $22 \mathrm{~B}$, but the fact that the phrase is about "you and me"; the verbal form would be the same if the pronouns did not occur in the phrase. This is the

18 The particle $\alpha$ i่น́ $\rho$ probably goes back, as Ruijgh (I97I: 716) suggests, to a petrified collocation of the adverb $\alpha \hat{\delta} \tau 1 \varsigma$ ( $\alpha \hat{\delta} \theta_{1 \varsigma}$ 'again', 'on the other hand') and the evidential particle óp $\alpha$, and serves as synonymous metrical doublet of the particle $\alpha$ tó $\rho$. But cf. Denniston (I954: 55),

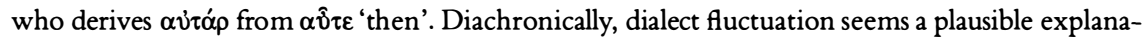
tion of the coexistence of the two allomorphs ( $\dot{\alpha} \tau \alpha \dot{\alpha} \rho$ being the Ionian, and $\alpha \dot{v} \tau \alpha \dot{\alpha} \rho$ the older Aeolic or even Mycenaean form): $\alpha$ v่ $\alpha^{\rho} \rho$ does not occur frequently outside epic discourse.

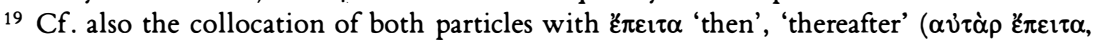

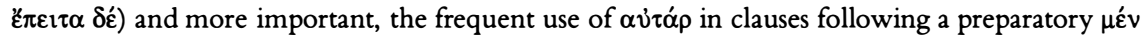
(e.g., Il. I I.99-IOI; I 7.609-I0; 20.458-60). See Chapter 4. 
consequence of the autonomy of the Indo-European word: each element in a phrase has in and of itself the form called for by the sense to be expressed." 20

Therefore, any overtly expressed subject in Greek, whether nominal or pronominal, is an addition to its verb, and especially a longer phrasing, with its rhythmical momentum and an intonational contour of its own, has a good chance of being realized as a separate unit, the verbalization of a single focus of consciousness. Thus a noun-epithet formula, like unit $b$ in the example just cited, remains a loosely added unit even when the pronoun is absent, as in the following case:

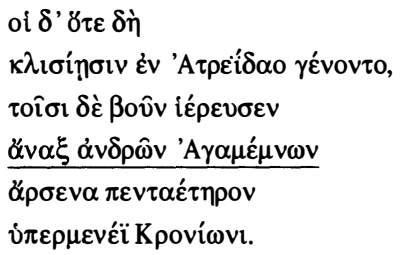

oi $\delta$ ' ठَદ $\delta \grave{\eta}$ and they, when

they were in the tent of Atreus's son

(and) for them a bull he sacrificed,

leader of men Agamemnon,

male, five years old,

to the all-mighty son of Kronos.

The same principle applies when the noun-epithet phrase offers new information, verbalizing the first appearance of a hero in a given situation. ${ }^{21}$ In the following example, the phrasing for Agamemnon in unit $b$ is not the subject of the preceding clause, any more than the following accusative phrase (unit c) is its object; both are items in a chain of additions supplementing the preliminary statement made in the preceding core clause: ${ }^{22}$

20 "Il n'y a pas besoin d'un sujet pour que $\varphi \hat{\alpha} \sigma \mathrm{\imath}$ 'on dit' soit au pluriel. Ce n'est pas l'apposi-

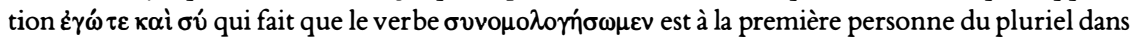
la phrase de Platon, Théag. I22 B, c'est le fait qu'il est question de 'toi et moi'; la forme verbale serait la même si les pronoms ne figuraient pas dans la phrase. Cela résulte toujours du caractère d'autonomie du mot indo-européen: chaque élément de la phrase a par lui-même la forme qu'appelle le sens à exprimer," Meillet and Vendryes I968: 598 . In the same passage the authors reject the notion of accord or syntactic agreement: the "subject" to a plural verb is necessarily plural itself, but independently of the verb, without there being any grammatical agreement. The general heading under which Meillet and Vendryes discuss these matters is "apposition"-a specific characteristic of Homeric Greek and early Indo-European-as opposed to the "rection" or "government" of later Greek styles and Indo-European languages. The opposition between apposition and rection states in the diachronic dimension what the opposition between fragmentation and integration (see Chapter 3 ) states in the context of the medial difference between speech and writing.

${ }^{21}$ On the poetic and ritual potential of noun-epithet formulas denoting first appearances, see Chapter 7 below.

22 See Meillet, who states (1937: 358-59) that any genitive, dative or accusative expression in a Greek sentence is no more governed by its verb than is an instrumental or locative phrase. The following passage is also discussed by Higbie (1990: 34) and was athetized by Zenodotus. 


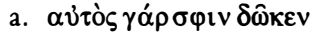

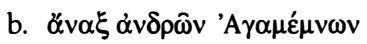

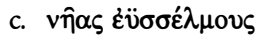

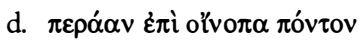

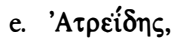

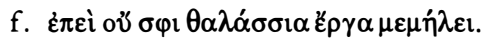

for he himself to them he had given [it], leader of men Agamemnon, the well-benched ships, to cross the wine-blue sea, the son of Atreus, since works of the sea, they were not on their mind.

One might consider some of these additions, especially the formulaic accusative phrase in unit $c,^{23}$ and the remarkable second mention of Agamemnon in unit e, to be metrically motivated. This may be true, but meter, as I shall argue in Chapter 6 , is the stylization of ordinary speech and not an artificial poetic construct. An analysis of formulaic elements as "metrically motivated" must therefore be handled with some circumspection: the final consideration, for the poet as well as for the researcher, must remain the function of these phrases in the stylized speech, which is the loose addition of detail to a preliminary core. Thus even if a phrase like unit e, which does not contribute as much to the flow of information as do the surrounding units, has been inserted primarily for metrical purposes, its status is still not that of a mere metrical stopgap that is inevitable in rapidly composed oral poetry. More precisely, it has that feature too, but phrases with a primarily vocal function and a diminished cognitive load are not confined to oral composition in performance; they are characteristic of speech in general. And the stylization of such phrases is just as important for the poet and his audience as is redundancy in general for ordinary speakers and their listeners. ${ }^{24}$

23 The Greek language can leave objects unexpressed when they are understood from the preceding context, where English has to use dummy objects like "him" or "it." See for example $I l$. 2.102-8, where the sceptre is understood as object after its mention in IOI but not expressed (see

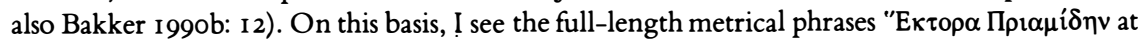
Il. I 5.604 and $\pi$ о $\delta \dot{\omega} \kappa \varepsilon \alpha \Pi \eta \lambda \varepsilon \dot{\varepsilon} \omega v \alpha$ at $I l .20 .27$ as added accusative namings rather than as direct objects governed by the verb in the clause before. Sometimes, however, the object in the core

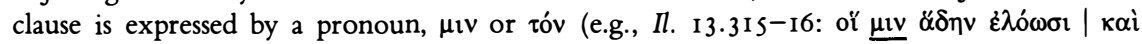

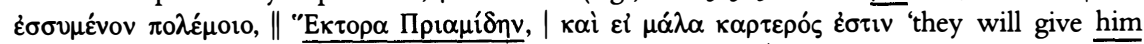
enough war to swallow $\mid$ fierce though he is $\|$ Hektor Priam's son | even though he is very strong').

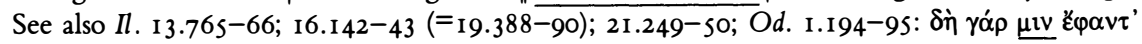

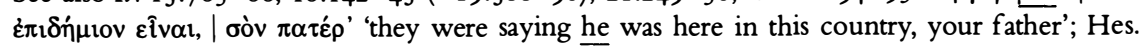
Theog. 696-97. Dative examples are Il. 20.321-22; Hes. Theog. 485-86.

${ }^{24}$ See also Bakker I990b: 8-10, and Chapter 8 below, where I make a distinction between units as additions and addition within units. Against meter as the ultimate artistic and communicative constraint on epic discourse see also Nagler 1974: xxi-xxii. 
Properties inherited from Indo-European syntax, then, facilitate the loose and fragmented speech that is in accordance with the processes of the human mind in general. Frequently, a piece of information, or cluster of interrelated ideas, is simply too large to be conceived of in consciousness as one synthetic, integrated whole; it has to be broken down into its component parts, by a principle that has been called by Chafe the "one new idea constraint": due to the limits of human consciousness no linguistic unit can contain two separate ideas, or distinct items of information. ${ }^{25}$ If a given complex idea contains two items of new information, these are most likely to be presented as two separate intonation units. The question what constitutes an idea, finally, will depend on the context within which something is focused on and verbalized. The idea of Agamemnon or of Atreus's son, for example, will be verbalized as a separate unit in a context in which the poet is concerned with tracking this character, as in units $b$ and $e$ in the extract last cited; but it will be part of a unit when the description of an event is called for, as in the case of "they were in the tent of Atreus's son" in unit $b$ of the example cited before. ${ }^{26}$

The wider implication of the observation that units can be added as details to a general picture is that the typical Homeric strategy, noticed by Krischer and others, of moving from the general to the particular has a clear function in the Homeric syntax of movement and close-up. The general orienting previews, which precede more detailed descriptions of scenes or sequences of scenes, are paralleled at the level of single scenes or events and their articulation in syntax, where we see a catalogue of additions to a clausal core. The core clause functions not as a flawed sentence to be repaired by subsequent additions, but as a starting point, a direction from which the detail added in later units is approached. The notion of a starting point or preview will remain central in our discussion: not only does it bind the syntactic and the suprasyntactic movement of Homeric discourse together, it also has more aspects to it than the preceding discussion has revealed.

25 Chafe 1994: 108-19, from which I borrow the term "one new idea constraint." See also Givón I984-9I: 258-63, for the "one chunk per clause principle," and DuBois I987: 826, for the "one new argument constraint" ("argument" being a linguistic term applying to the complements of the verb: subject, object, indirect object).

26 Another factor determining whether or not a given idea will be verbalized as a single phrase is the phonetic contour or informational richness of the words involved. See for example Chafe 1994: I 46-60; Devine and Stephens 1994: 4I4. There is also the rate or delivery of speech as the cause of the distribution of information across two units, where another speech style would result in one unit (see Chapter 6 below). 


\section{Frames and Goals}

Names, as we have seen, frequently follow clauses in the flow of speech, acting as additions to a clausal core unit. But the reverse is also true, and this arrangement is no less frequent or important. The name itself may act as a frame, preceding instead of following its clause. For this use, which involves another aspect of the tracking of participants in the epic story, the simple name, rather than the noun-epithet formula, tends to be used. The name is marked by the particle dé or autár as a new step in the progression of the narrative, a step signaling that the god or hero in question will be the frame, or theme, for the moment or moments to come. ${ }^{27}$ The study of such preceding names, as long as it does not mistake them for the subjects of their clauses, may lead to a change in view that is similar to that of the added, right-dislocated names discussed above. Instead of being leftdislocated elements, false starts, or otherwise deviations from a sentential norm, such names are units in their own right that are uttered for a purpose. One common function for a framing, preposed unit is contrast, as in the following simple example:
a. $\ddot{\omega} \delta \dot{\delta} \mu \grave{\varepsilon} v \ddot{\varepsilon} v \theta \alpha \kappa \alpha \theta \varepsilon v \delta \delta \varepsilon$

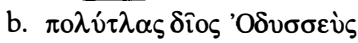

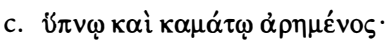

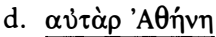

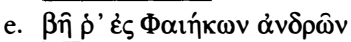
f. $\delta \eta \hat{\mu o ́ v ~ \tau \varepsilon ~ \pi o ́ \lambda ı v ~ \tau \varepsilon, ~}$

so he, he slept there, much-suffering godlike Odysseus, worn out with sleep and fatigue, but [as for] Athene, she went to the Phaeaceans' people and city.

$(\mathrm{Od} .6 . \mathrm{I}-3)$

Examples like this provide evidence that such verbal figures as chiasmus (the arrangement of two pairs of elements in an order $a b b a$ ) and hysteron proteron (the reversal of a natural order) are not by themselves a matter of style in the sense of literary embellishment used by philologists; they are

27 Notice that for this reason such elements have themselves been called themes (e.g., Dik I989: I35; Halliday 1967), by a metonymy not unrelated to that of topic, as discussed above. Geluykens (I992: 33-8I) off ers extensive discussion of preposed constituents (a phenomenon he calls left-dislocation). The concept of framing used in the present discussion covers the three main functions attributed to left-dislocation by Geluykens: referent introduction, recoverability (function with respect to the preceding discourse), and topicality (function with respect to subsequent discourse). Geluykens (I992: 100-108) discusses left-dislocated elements as separate tone groups (intonation units, in the terminology used here), dealing with the phenomenon that serves as the basis for stylization in Homeric discourse. 
quite normal in living speech, where they result from a natural sequence in the flow of ideas and their verbalization. The mention of Odysseus's name (unit b) triggers the name of the other participant from previous scenes, and that name is verbalized (unit $\mathrm{d}$ ) in direct contrast with what precedes, and so must come before its own clause. The example deserves special notice, furthermore, in that it contains a feature pertaining to the framing function of unit $\mathrm{d}$ that survives the recording of speech into text: the particle $r h(a)$ in unit $\mathrm{e}$. This enclitic is postpositive and it marks an intonational boundary; as such it is restricted, according to Wackernagel's Law, to the second place in the clause; the analysis of the preceding name as a separate unit reveals that instead of constituting an exception (fourth place in a sentence beginning with autàr Athêne as its subject), the enclitic is used in accordance with the law, in the second position of a clausal unit uttered within the frame of the previous one that is prosodically distinct. ${ }^{28}$

The following example is a more complicated case of chiasmus. The chiastic structure involves two pairs of items, two agents and two patients in a particularly complex killing-scene. The two pairs are arranged in the order $\mathrm{A}^{1} \mathrm{p}^{1} \mathrm{p}^{2} \mathrm{~A}^{2}$ and the whole stretch of discourse is under the scope of one preposed, framing unit:

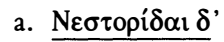

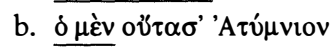

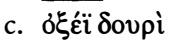

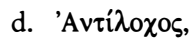
e. $\lambda \alpha \pi \alpha \dot{\rho} \rho \eta_{\varsigma} \delta \dot{\varepsilon} \delta ı \dot{\eta} \lambda \alpha \sigma \varepsilon$

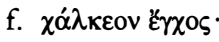
g.

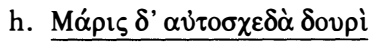

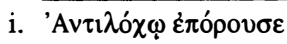

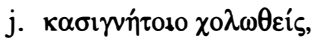
k. $\sigma \tau \grave{\alpha} \varsigma \pi \rho o ́ \sigma \theta \varepsilon v \vee \varepsilon ́ \kappa v o \varsigma$.

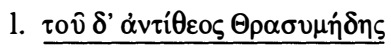

and the sons of Nestor,

he, he wounded Atumnios,

with the sharp spear,

Antilokhos,

and he drove it through his flank

the bronze spear,

and he fell before him,

and Maris from nearby with the spear,

he rushed at Antilokhos,

angry because of his brother,

putting himself before the body,

and him godlike Thrasumedes,

${ }^{28}$ See Ruijgh I990: 229-3 I. In addition to the examples he cites (Il. 5.748; I6.220-2I [see below]; Od. 8.55-56, 449-50; I0.24I-42) and the example in the text, cf. also: Il. 2.3 I0; 5.849; I0.73; II.IOI; I4.462; I6.307-8, 466; 20.484; 2 I.I 7, 205; Od. I 8.66-67; 19.209-Io; Hes. Theog. 226, 55I. See also Bakker I990b: I2-I4. Another recorded feature pointing to the extraclausal, framing status of units is the modal particle $\kappa \varepsilon(v)$ or ớv, equally enclitic (Ruijgh I990: 232; Devine

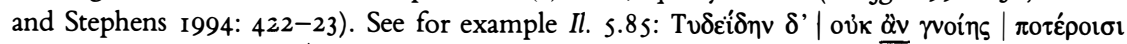
$\mu \varepsilon \tau \varepsilon i \eta n$ 'And Tydeus's son | you could not have known | among whom he was', a case of prolepsis, on which see Panhuis 1984; more literature on prolepsis is cited in Slings I992: IO5 n. 46. 


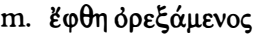
n. $\pi \rho i v$ ovं $\alpha_{\alpha} \sigma \alpha \mathrm{l}$,

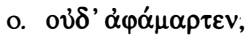
p. $\hat{\omega} \mu o v \not \alpha \varphi \alpha \rho$.

he was bef orehand in reaching, before [he could] wound [him], and he did not miss, the shoulder from nearby.

Three times a frame is opened here by a preposed name (units $a, h$, and l), and each time that moment is marked as one of continuation (notice the particle dé). The joint action of the two sons of Nestor is appropriately framed by the a-unit Nestorídai d' 'and the sons of Nestor'. Traditional grammar would call this phrase a pending nominative or dislocated subject, which is cut loose from the network of the syntactic construction and causes an anacoluthon. ${ }^{29}$ It would be better to see this phrase as establishing the theme of the upcoming description: the joint slaying of one pair of brothers by another. Unit a is a new step (marked by dé) not only in the sense that it verbalizes a new detail coming into focus but also because it accommodates such detail. The unit marks a new item in a catalogue of killings and at the same time holds together the catalogue of details pertaining to this particular double killing.

The first of these details verbalized in the space opened up by Nestorídai $d^{\prime}$ is a statement with the particle mén, of the type that we discussed at the end of the previous chapter. Its processual force is particularly clear: rather than being referential ("the one," antithetically opposed to "the other"), the phrase is a starting point at the onset of the narrator's movement along the narrative track previewed by the a-unit. ${ }^{30}$ The first stage of this "Nestorid track" is the pairing of the first brother with his victim. It consists of three steps that verbalize new detail coming into focus (units b, e,

29 E.g., Kühner and Gerth I 898-I904: I:47. A particularly clear example of this phenome-

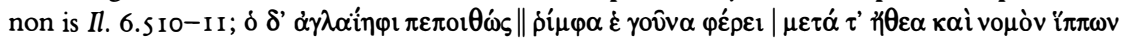
'and he, confident in his splendor \| lightly his legs carry him | along the abodes and pasture of horses', cited and discussed by Slings I992: 96-100. The cognitive complexity of "lightly his feet carry him who is confident in his splendor" would violate the one idea per unit constraint; the result is a division into two foci of consciousness, whereby the verbalization of the first contains an "ungrammatical" dangling nominative and participle. For another pending nominative and an "ungrammatical" change of subject, see Il. 5. 27-29.

${ }^{30}$ Of course, the use of $\delta$ $\mu \varepsilon ́ v$ in unit b is similar to classical Greek's referential use of $\mu \varepsilon \dot{\varepsilon} . \ldots \delta \dot{\varepsilon}$, in that the mentioning of "the one" brother creates the anticipation that "the other" will be mentioned. The point is, however, that the two sons of Nestor are not opposed to each other as two referential objects. 
and $\mathrm{g}$ ), and three adding units that either zoom in on this detail (units $\mathrm{c}$ and f) or serve the disambiguating function that we discussed above (unit d). ${ }^{31}$

Instead of continuing with "And the other brother, Thrasumedes, he killed Maris, who rushed at Antilokhos . ..," the narrator proceeds with the brother of the victim, set up as frame (unit h) triggered by the idea of the victim just verbalized. This new frame is a subframe within the encompassing frame. It establishes Maris for four units as the new agent or protagonist in this complex scene. One might want to consider Máris as the subject of the verb epórouse 'rushed at' in the next unit. As noted above, however, in the appositional syntax of Homeric Greek this verb and its clause do not need an overt name for them to be "complete"; moreover, when additional adverbial detail is involved that situates Maris vis-à-vis the killer of his brother (autoskhedà douri ' from nearby with his spear'), the total amount of information becomes simply too much for one unit: introducing a character on the scene and telling what he did requires at least two units by the "one idea constraint" mentioned above.

In the third subframe (unit l), the idea of Maris, the agent of the previous subframe, expressed as a pronoun in an oblique case (to $\hat{u} d^{\prime}$ ) serves as stepping-stone for the appearance of Thrasumedes, linking this new agent to the previous discourse. The naming of Thrasumedes, serving as frame for the four units to follow, is itself directly linked to the overarching frame in unit a. Because he is one of the Nestorids, the idea of Thrasumedes was already partly activated by the activation of the Nestorid track in unit a. ${ }^{32}$ In such cases, Chafe speaks of a semiactive state, in which one is "peripherally aware" of something within the context of something else. ${ }^{33}$ The overall structure or movement of the whole passage as framed by unit a is thus $\mathrm{A}^{1} \mathrm{p}^{1} \mathrm{p}^{2} \mathrm{~A}^{2}$ : the activation of Antilokhos $\left(\mathrm{A}^{1}\right)$ is a starting point: it raises the expectation as to "the other brother" $\left(\mathrm{A}^{2}\right)$ and so indicates a goal. This goal is then reached via the intervening description of the two victims $\left(\mathrm{p}^{1} \mathrm{p}^{2}\right)$. We shall see later in this chapter that the indications of goals and the

${ }^{31}$ Notice that the naming of the first agent $\left(\mathrm{A}^{1}\right.$ in the chiastic arrangement $\left.\mathrm{A}^{1} \mathrm{p}^{1} \mathrm{p}^{2} \mathrm{~A}^{2}\right)$ actually follows the naming of the first patient in unit $\mathrm{b}$.

32 The literature on pragmatics abounds in mentions of this phenomenon, the activation of concepts in association with a theme or set of expectations. See Schank and Abelson 1977: 4I; Tannen 1979; Prince 198I; Chafe 1987: 29. Frames often create a context in which the use of definite pronouns is possible or appropriate (e.g., talk about "wheels" within the context of a given car set up as frame).

${ }^{33}$ Chafe I987: 28-3I; 1994: 53, 7I-76. 
movement toward them through intervening space is a wide-ranging feature in the speech syntax of Homeric discourse.

As further illustration that our idea of sentential syntax is irrelevant for what the epic narrator wants or needs to achieve, consider the way in which Circe presents the dangers of Skulla and Kharubdis to Odysseus:
a. oi $\delta \dot{\varepsilon} \delta v ́ \omega \sigma \kappa o ́ \pi \varepsilon \lambda o r$

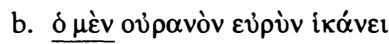

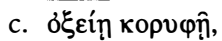

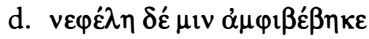
e. Кำย́́n.

and the two peaks,

the one, it reaches into the sky, with sharp summit, and a cloud, it stands around it a black one

(Od. $12.73-75)$

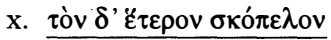
and [as for] the other peak

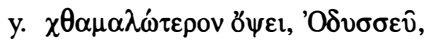 you'll see it lower, Odysseus,
z. $\pi \lambda \eta \sigma i o v \dot{\alpha} \lambda \lambda \dot{\eta} \lambda \omega v$. [they are] close to each other.

(Od. I $2.10 \mathrm{I}-2)$

With unit a the speaker does not start a sentence that goes awry and loses itself in anacoluthic confusion (mén being separated from "its" dé by 28 metrical lines). Nor would a genitive phrase for unit a ("and of the two peaks the one ..., the other") have been grammatically more "correct." 34 The a-unit is an orienting frame and unit $b$ a clausal unit uttered within it. Unit $b$ looks ahead to the other rock and places the description of Skulla and her abode in the right perspective. Again, we see a strategy of framing and goal-seeking in which the specific detail selected for verbalization is framed and accommodated by a global preview. In the following example, Tros the son of Alastor beseeches Achilles not to kill him. Here the initial frame (unit a) is an accusative phrase:

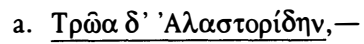

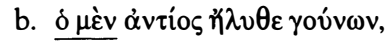

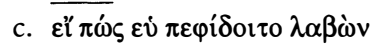

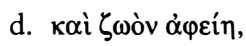
e. $\mu \eta \delta \dot{\varepsilon} \kappa \alpha \tau \alpha \kappa \tau \varepsilon i ́ v \varepsilon 1 \varepsilon v$
f. $\delta \mu \eta \lambda \iota \kappa i ́ \eta v \varepsilon \dot{\varepsilon} \varepsilon \dot{\eta} \sigma \alpha \varsigma$,

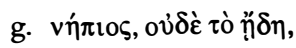

${ }^{34}$ Cf. Russo 1994: 382-83.
Tros the son of Alastor (acc.),

he, he came up against his knees,

in the hope that he would spare him taking him prisoner, and let him go alive, and not kill him, taking pity on a man his own age, misguided soul, and he did not know this 
h. ō ov่ $\pi \varepsilon i ́ \sigma \varepsilon \sigma \theta \alpha \mathrm{l}$ है $\mu \varepsilon \lambda \lambda \varepsilon v$.

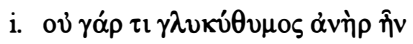

j. ov่ $\delta$ ' $\alpha \gamma \alpha v o ́ \varphi \rho \omega v$,

k. $\dot{\alpha} \lambda \lambda \dot{\alpha} \mu \alpha{ }^{\prime} \lambda{ }^{\prime} \varepsilon \mu \mu \varepsilon \mu \alpha \dot{\omega} \varsigma$.

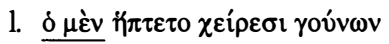

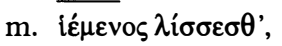

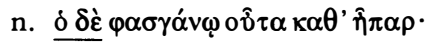

that he was not going to persuade him

for this was not a sweet-hearted man

nor kind-spirited,

but one in a rage,

he, he touched his knees with his hands

eager to supplicate,

and he, he thrust his sword in the liver.

(Il. 20.463-69)

When we view this passage as a sentential structure, we would have to say that the accusative of unit a is dislocated from a verb which does not occur until unit $\mathrm{n}$ (outa 'stabbed'). More in line with the flow of the passage, however, is to take the a-unit as a frame within which other units are uttered, one of them containing the logically central verb. This is not to say that Trôa d' Alastoríden 'Tros the son of Alastor' is complete as it stands: the phrase obviously needs complementation of some sort. The important point, however, is that judging phrases by their syntactic completeness or incompleteness is a practice betraying the literate bias discussed in previous chapters. Linguistic expressions, as I will propose more fully in Chapter 7 below, are not so much "things" as behaviors that have no meaning outside the context in which they are performed. In the present context (a description of Achilles wreaking havoc among the Trojans) an accusative phrase marked off by intonational boundaries can mean only one thing: a new victim of Achilles is coming into focus. And this contextually determined activation will ensure that the hearer is sufficiently oriented in the upcoming description. ${ }^{35}$ Within the frame we witness a series of additions held together by the repeated ho mén (units $\mathrm{b}$ and $\mathrm{l}$ ), keeping the attention of the hearer focused on the participant activated by the framing unit, until finally in unit $\mathrm{n}$ (marked by ho dé) the jump can be made to the agent and the details of the killing. ${ }^{36}$ Note that the description of the killing of Tros comes in three parts: the frame (unit a); a focusing on detail pertaining to the victim (units $\mathrm{b}-\mathrm{m}$ ); and the killer and the killing (unit $\mathrm{n}$ and beyond). As we shall see later in the chapter, this tripartite structure appears to be a constant in the deployment of Homeric narrative.

Scenes such as the ones framed by the names of the Nestorid brothers

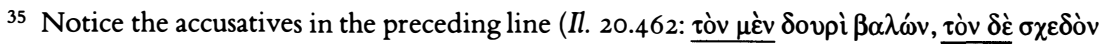

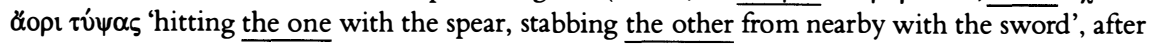
which unit a in the text can be read "and as for Tros son of Alastor").

${ }^{36}$ For this use of $\mu \varepsilon \dot{v}$, see Chapter 4. 
and Tros in the preceding examples are killing scenes involving two participants or parties: a victor and a victim. Accordingly, the framing unit may also consist of two names. Consider, for example: ${ }^{37}$

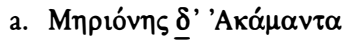

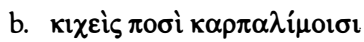

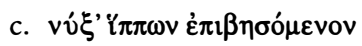
d. $\kappa \alpha \tau \grave{\alpha} \delta \varepsilon \xi$ iòv $\hat{\jmath} \mu o v$.

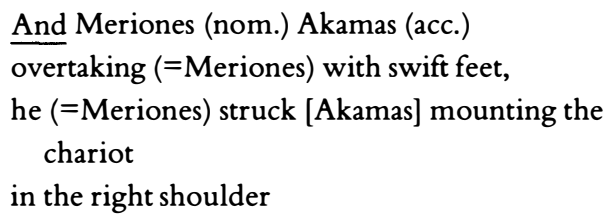

(Il. $16.342-43)$

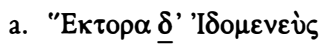

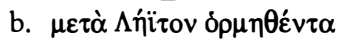
c. $\beta \varepsilon \beta \lambda \dot{\eta} \kappa \varepsilon \imath \theta \dot{\theta} \rho \eta \kappa \alpha$
d. $\kappa \alpha \tau \grave{\alpha} \sigma \tau \hat{\eta} \theta 0 \varsigma \pi \alpha \rho \grave{\alpha} \mu \alpha \zeta o ́ v$.
And Hektor (acc.) Idomeneus (nom.) rushing (=Hektor) after Leïtos: - he (=Idomeneus) hit [Hektor] on the corslet, on the chest near the nipple.

In these cases, a-units frame the passages and orient the listener, providing global indications of the scene, and then added units of familiar types and functions offer close-ups: participial phrases (b-units) with detail pertaining to the target or victor; prepositional phrases (d-units) zooming in on the place of the blow; and clausal c-units that verbalize the event proper. Like the verb of wounding (outa) in the description of the killing of Tros that we discussed above, the verbs in the c-units here, núks' and beblékei, are not the "verb" of their sentences, governing a subject and an object from which they are separated by the end of the metrical line. As we saw above, the noun phrase in Homeric Greek is more autonomous than in later Greek or in English, having a tendency to contract a relationship of agreement with a verb (sometimes across a unit boundary), rather than one of government (within a linguistic unit, such as the sentence). ${ }^{38}$

Thus the a-units, even though they are "incomplete" from a strictly syntactic point of view, are perfectly intelligible in this particular context; they stage the two participants, along with their roles (agent or patient) as marked by inflectional morphology, in the upcoming killing-scene. In the

37 See also Bakker I990b: I4-I6. Notice that the examples differ in that in the second case "Hektor" is active or given information and "Idomeneus" is new information.

38 Lehmann I993: 216, building on Meillet's observations (1937: 358-59), relates this autonomy of the word in the phrase to his own argument that Proto-Indo-European was an "activepassive language," a language with nominal inflection that codes not grammatical roles (subject, object) but semantic roles (agent, patient). 
terminology developed here, the names in each a-unit serve as starting points for the transformation of the scene into language. The verbs in the c-units, conversely, do not need the names as "complementation": after all, what seems to us a single verb (núkse) can represent an utterance on its own with a subject and an object ("[he] struck [him]"), given the appropriate context. Such a context is in this case, of course, provided by the a-units, which in their turn are uttered within a context that determines their meaning and serves as an interpretive frame: the context of catalogic battle narrative, in which pairs of warriors are staged and indicated as frames for the scenes to come. ${ }^{39}$ As always in the flow of speech through time, any unit is uttered within the context of its immediate past and provides, in its turn, context for its immediate future.

If one accepts that the a-units in these passages function not as subjects and objects of a sentence, but as frames for a scene, one's reading of the following passage might be altered accordingly: ${ }^{40}$

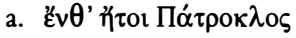
b. $\dot{\alpha} \gamma \alpha \kappa \lambda \varepsilon ı$ เòv $\Theta \rho \alpha \sigma \hat{u} \mu \eta \lambda o v$,

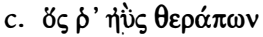

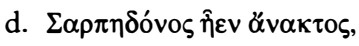

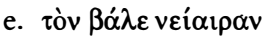
f. $\kappa \alpha \tau \grave{\alpha} \gamma \alpha \sigma \tau \varepsilon ́ \rho \alpha$,

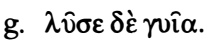

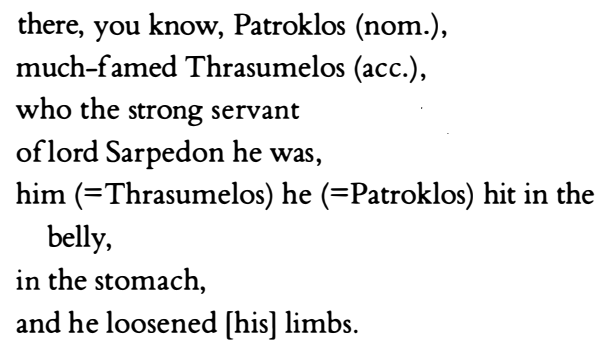

(Il. I6.463-65)

In such cases, the temptation is to see the verb (bále in unit e) as postponed. The result is a reading of the passage as an anacoluthon, a deviation from a sentential norm that is either condemned or accepted by calling it an oral

39 In catalogic battle narrative, the idea of killing, in other words, is given: present and active in the performer's consciousness and assumed to be present and active in the audience's mind as well. Concepts that are given and active will need only attenuated expression, or no expression at all, in the phrasing of the focus of consciousness in question. On "given" in the sense of "active," see Chafe 1980: I0; 1987: 26-31; 1994: 72. On the given status of verbs of killing in battle narrative, see also Chapter 8 .

${ }^{40}$ See also Il. 5.76-83; I I.I 22-27, 32 I-22; I 3.427-35; I 4.409-I 2; I 5.430-34; I6.40 I-IO (see Bakker I 993b: 4-I 2); I 7.306-9, 6I0-I7 (the most complex case). Notice that in many cases the victim is a charioteer hit accidentally, a frequent incident in Iliadic battle (Fenik I968: 204). On processual $\ddot{\varepsilon} v \theta(\alpha)$ 'there' and $\ddot{\eta} \tau o t$ in unit a, see the relevant notes in Chapter 4 . Only here and in the nearby $I l$. I6.399 (a good case of clustering, cf. I6.3 I4, 322) do we find the collocation of these two particles. 
anacoluthon. ${ }^{41}$ The anacoluthon in this passage disappears when considered in light of the two previous examples. Notice, first of all, the structural similarities. After the two participants are named, detail pertaining to the victim is added, but as an appositive relative clause (units $\mathrm{c}-\mathrm{d}$ ) this time, not in the form of a participial phrase. It is this syntactic difference that makes the pronoun ton in unit e necessary to avoid confusion. Rather than a change in construction or a repair strategy, however, the relational demonstrative clause tòn bále neíairan reflects a purposeful strategy, situating the verbalization of the present moment within the context of the immediately previous discourse. In other words, the verbalization of detail pertaining to Thrasumelos has created a second frame, a subframe within the confines of the first, encompassing frame. It is the pronoun that acknowledges the second frame as such; its function is not so much to mark the transition to a new frame (note the absence of dé) as to signal the moment that was anticipated when the narrator set the first frame: a close-up, rather than a new step. The details of the killing proper, then, can be seen as the final stage in a three-stage process: frame (or starting point), subframe, and a goal to which both frames are aiming. This characterization has the merit of bringing out the common element in many seemingly unconnected phenomena in the syntax of Homeric speech and composition. Before we continue our discussion of frames and goals, however, one more function of framing-names in Homeric discourse has to be briefly discussed.

\section{The Syntax of Activation}

The framing-name in lists of warriors slaying and slain in the battle typically sets up a character who is new to the stage as theme for discourse to come, the agent or patient in a killing-scene. But framing-names may also verbalize a return to a character, a reactivation of the concept of a character. Since we have already applied this concept to added names, a brief differentiation of the various possibilities might be useful here. The simplest and easiest transition from one protagonist to another, as we saw in the previous chapter, is a simple topic switch without names (ho dé 'and he'). In this case, both characters are present on the scene currently in focus

${ }^{41}$ For instance, Janko 1992: 276. Kirk (1962: I69) calls the similar passage Il. 17.610-I7 "some of the weakest battle-narrative in the Iliad." 
and are fully active in the minds of the narrator and the audience, so they need not be explicitly named. When the second character has been out of sight for a short while, without the scene in question having been changed, that character's name may be added to the ho dé clause. In such cases we might say that the second character has become near-active in the minds of speaker and audience. The added name, signaling the transition to the active state, is meant as a reminder, to keep the narrative on the right track. When more time has elapsed since the last mention of a character, and when different scenes have been described in the meantime, we may say that the character is returning, and that in the minds of the narrator and the audience the idea of the character is activated from a semiactive state, the status of an idea of which one is peripherally aware. The verbalization of such a moment typically involves a framing-name that functions as signpost on the narrative track. ${ }^{42}$ The name is normally without an epithet, and marked by dé or autár as a moment of continuation. In the examples that follow, both the return of Odysseus to the narrative after Thetis's visit to Achilles and the return of Achilles after a description of the Myrmidons marching into battle are marked by autár.

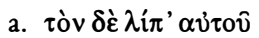

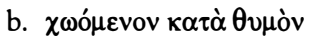

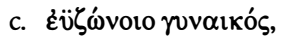

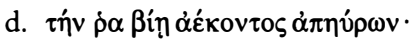

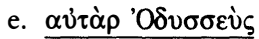

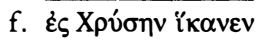

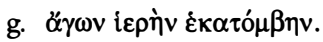

and him she left there, raging in his heart, about the fair-girdled woman, her they had taken by force against his will, but Odysseus, he reached Khruse, leading the sacred hecatomb.

(Il. I.428-3 I)

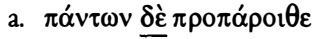

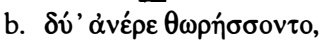

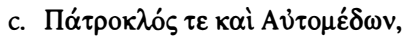

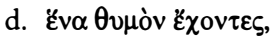

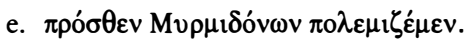

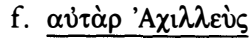

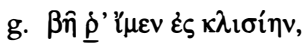

and ahead of all of them, two men, they marched in armor, Patroklos and Automedon, being one in their fury, to fight in front of the Myrmidons, but Achilles, he went to his tent.

(Il. I6.218-2I)

${ }^{42}$ Lambrecht (1987: 23I-35) uses a similar distinction between framing and added names (topics and antitopics in his terminology), considered in terms of recoverability (the participant being less recoverable in the case of framing). 
In these examples we see a switch back to a major character, who is thus once more set up as protagonist after a given interval. The switch moment is constituted by autár and the name of the returning hero (unit e in the first passage and unit $f$ in the second). Rather than being the subjects of an enjambing clause (they occur at the end of the metrical line), these units serve as frames for what lies ahead. ${ }^{43}$ In the first example, the narrator resumes the thread (the return of Khruseïs to her father by the embassy of Odysseus) that was left at Il. I.3 I2, before the attention was directed to Thetis's visit to Achilles. In the second example Achilles is set up, after scenes describing the preparation of the Myrmidons for battle, as the agent in a brief scene setting the perspective for the following Patrokleia. In both cases a separate unit is devoted to the narrative act of returning to Odysseus and Achilles, reflecting the cognitive effort that is involved in the reactivation. ${ }^{44}$

Finally, characters may also make an entirely new appearance on the stage, coming out of absence into presence, or in cognitive terms, becoming an active concept in the minds of the narrator and his audience out of an inactive state. In the specific context of catalogic battle narrative, as we have seen, the normal method of verbalization is the simple framing-name, serving as label: the name of either the agent or the patient, or both names combined within one unit. Another frequently used method for effecting the new appearance of a hero is the noun-epithet formula, preceded by a unit in which the relation of the new character vis-à-vis the character already present is specified, most often a relation of seeing;

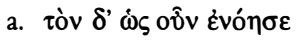
and him (=Diomedes) when he (=Pandaros) saw,

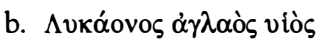
the radiant son (=Pandaros) of Lukaon

The new character, named in unit b, sees somebody who is currently in focus. But rather than reporting an act of perception, the a-unit serves as link or transition between the new character and the one already present, who is verbalized as a demonstrative pronoun in an oblique case. In Chapter 7 we will discuss in detail the pragmatics and poetics of such moments, which are of prime importance in the epic tale. Here we simply observe

${ }_{43}$ Notice the particle $\dot{\rho}(\alpha)$ in unit $g$ of the second example, confirming that unit $f$ is intonationally independent.

${ }^{44}$ Chafe (I994: 7I-8I) speaks of "activation cost" in this connection. 
that noun-epithet formulas preceded by such a relational clause are an important way of introducing new characters on the scene.

We have discussed various ways of making transitions to a character in the Homeric narrative. The different methods available for verbalizing such transitions reflect both the status of the character in the narrative and the way in which poet and audience conceptualize the character. For example, if s/he is present in the narrative, a character will be active in the consciousness, and a transition to the character will be verbalized in a certain way; a returning character will be semiactive in the consciousness, and the transition will be verbalized accordingly. The four possibilities may be schematically summarized as follows: ${ }^{45}$

\begin{tabular}{|c|c|c|}
\hline $\begin{array}{l}\text { Character } \\
\text { in the nar- } \\
\text { rative }\end{array}$ & $\begin{array}{l}\text { Character } \\
\text { in the } \\
\text { consciousness } \\
\text { of poet and } \\
\text { listeners }\end{array}$ & Verbalization \\
\hline present & active & 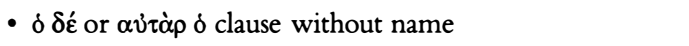 \\
\hline copresent & near-active & $\begin{array}{l}\text { - } \delta \delta \varepsilon ́ \text { clause + name in same unit } \\
\text { - } \delta \delta \varepsilon ́ \text { clause + noun-epithet phrase in next unit } \\
\text { - answering-formula + noun-epithet phrase in next unit }\end{array}$ \\
\hline returning & semiactive & - simple name with $\delta \varepsilon \dot{\varepsilon}$ or $\alpha$ v่ $\alpha \dot{\rho} \rho+$ clause in next unit \\
\hline appearing & inactive & 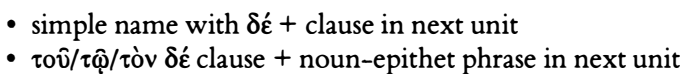 \\
\hline
\end{tabular}

This schema is merely meant to represent the findings of the preceding pages. It is approximate and does not pretend to predict the precise way in which a given transition to or (re)appearance of a character is articulated in speech syntax. In the end, living discourse defies neat categorization and always produces exceptions for which no special explanation or justification seems available. ${ }^{46}$ But that should not keep us from making some generalizations.

45 Note that the category "near-active" in the second column has been added to Chafe's categories of "active," "semiactive," and "inactive." Chafe (1987: 25-36; 1994: 7I-76) relates these terms to "given," "accessible," and "new" information, respectively.

46 For example, in Il. I.488-89 the reappearance of Achilles after Odysseus's trip to Khruse (see the example above) is not verbalized as a framing name but as an amplified noun-epithet 


\section{Explanation and Epic Regression}

As the last step in our overview of framing phenomena in Homeric speech syntax, we turn from preposed names to the particle gár. This element of Homeric discourse is seemingly quite unrelated to the framing phenomena discussed thus far, yet it will yield a discussion that leads to the same goal as many of the demonstrations above. J. D. Denniston describes what he calls confirmatory and causal gár as "commoner in writers whose mode of thought is simple than in those whose logical faculties are more fully developed. The former tend to state a fact before investigating its reason, while the latter more frequently follow the logical order, cause and effect." " And indeed we frequently find gár in Homer (one of the "writers" meant), though not as the marker of a "cause" after its "effect," and even less as the reflex of a prelogical, primitive mind. Rather than marking causes or reasons, gár is an important element in the flow of speech itself, where it is used to mark moments at which looking more closely at the point reached so far on the path of speech (i.e., movement into a frame) may take the form of an explanation added to what precedes. And far from being illogical, such added explanations are a key part in the logic of movement in speech: the purposeful exploration of a well-chosen, strategic starting point from which the narrator and the audience orient themselves.

A clause marked by gár may be no more than additional visual detail pertaining to the picture verbalized in a preceding unit. In such cases the explanation is a detail added to a frame, and not very different from the adding units verbalized to zoom in on the scene before the speaker's eyes, which we discussed earlier.

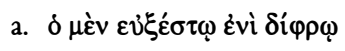

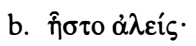
he in his well-polished chariot,

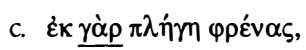

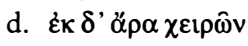

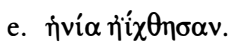
he sat crouching,
for he was knocked out of his wits,
and from his hands,
the reins they had slipped.

(Il. I6.402-4)

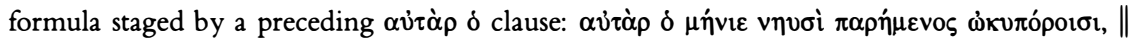

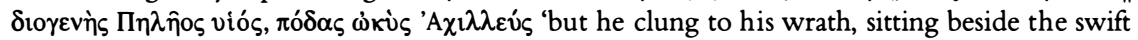
ships, divinely born son of Peleus, swift-footed Achilles'. Similarly, the return to Odysseus and Eumaios at Od. I 5.30I, after 300 lines of intervening scenes, is verbalized as an added, not as a framing name.
}

47 Denniston I954: 58. 
The gár clause in unit c verbalizes a closer look at the scene depicted in units $\mathrm{a}-\mathrm{b}$ and thereby explains that earlier perception. ${ }^{48}$ Clauses with gár may be used to complement the general picture, filling in the frame presented by the previous clause. We have seen how an earlier clause often serves that purpose, offering a global preview of the scene in question. The death of Patroklos provides an instructive example: ${ }^{49}$

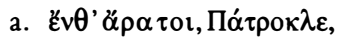
there for you, Patroklos,

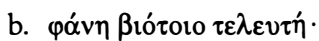
the end of your life, it appeared,

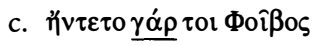
for Phoibos came face to face with you,

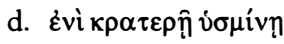

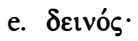

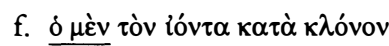
in the strong battle,
terrible,
and he (=Patroklos) him moving (=Phoibos)
through the crowd

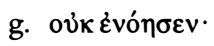
he did not see
h. $\eta \dot{\varepsilon} \rho \imath \underline{\gamma \alpha} \rho \pi 0 \lambda \lambda \hat{n}$
for in thick mist

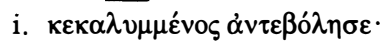
covered he (=Phoibos) came against him:
j. $\sigma \tau \hat{\eta} \underline{\delta}^{\prime} \partial^{\prime} \pi \mathrm{\imath} \theta \varepsilon v$,
and he stood behind
k. $\pi \lambda \hat{\eta} \xi \varepsilon v \underline{\delta \varepsilon} \mu \varepsilon \tau \alpha \dot{\alpha} \varphi \rho \varepsilon v o v$
and he struck his back.

(Il. I6.787-9I)

After a general indication of the scene in units a and $b$, the participants are staged in units $\mathrm{c}-\mathrm{i}$, with two gár statements (units $\mathrm{c}$ and $\mathrm{h}$ ) filling in the picture, along with a preparatory mén clause (unit $\mathrm{f}$ ). Only at the point reached in unit $j$ does the description of the event itself begin, and it is this moment that the narrator anticipates when uttering units $a$ and $b$. Those units, then, are not merely a starting point; they are at the same time pointers to a goal, indications of the direction the discourse is taking. And far from being mere explanations, loosely added to a fact that would otherwise remain unclear, the gár statements are entirely bound up with the syntax of movement: they cover the narrative space between the neardistance goal and the point from which it begins to come into focus. ${ }^{50}$ The

${ }^{48}$ One could imagine the c-clause expressed as a participle, adding detail to the participle in the previous clause. Notice the presence of $\mu \varepsilon v^{v}$ in unit a. For another combination of $\mu \varepsilon^{\prime} v$ and $\gamma \alpha \dot{\rho} \rho$ see Il. 17.366-68.

${ }^{49}$ For the "apostrophe" in units a-c, see Bakker I993c: 23, focusing on the use of the evidential particle đó $\alpha$ in unit a. Note that the scene in which Patroklos dies is preceded by an evidential subclause marked by $\delta \dot{\eta}$, which in turn is preceded by an instance of the three-times motif. This whole climactic and pivotal event is marked throughout by a clustering of evidentiality phenomena.

${ }^{50}$ Cf. Lang's remarks (1984: $5-12$ ) on digressions in Herodotus. It is customary in the 
passage, then, could be called a three-stage process, just as the deaths of Tros and Thrasumelos discussed above: it consists of a starting point, a goal, and the movement from the one to the other.

Often this movement implies the reversal of temporal sequence: the gár statement may involve events that took place, chronologically, before the event that has been set up as goal in the initial, framing unit. This phenomenon has been called, in a discussion not dealing with speech syntax but clearly relevant for our present purpose, epic regression, the presentation of events in reverse chronological order. ${ }^{51}$ What is not reversed, however, is the attention of the narrator, who is really looking forward rather than back; rather than dealing with a historical digression, a swerving off the narrative track, the narrator is engaged in a purposeful strategy for better approaching the highlights on the track.

Given these considerations, it is not surprising that gár is particularly at home in the vicinity of the starting point of all starting points, the very beginning of the epic tale. It is here that choosing the right vantage point, sufficiently global but also sufficiently relevant and specific, is particularly important, if one wants to avoid a presentation of events $a b$ ovo that is not only dull but often also impossible, as the Homeric narrator and most other storytellers realize. Explanatory goal-seeking statements with gár are a natural consequence of the fact that at the beginning, when the story has not yet acquired the momentum it will have later on, looking ahead at goals to be reached in due course is as yet more important than the covering of actual distances.

Thus during the first moments of the Iliad, after the preliminary statement that it was Apollo who brought about the harmful encounter between Achilles and Agamemnon (Il. I.8-9), it is a gár statement (9) that leads the way in the direction of the goal set up by that preliminary statement: the description of the plague sent by Apollo $(5 \mathrm{I}-52)$ and the reason for Achilles to call the army to the assembly (53), an event that is, again, previewed and approached by a presentation of events in reverse order:

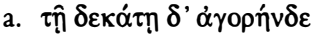
and on the tenth day to the assembly

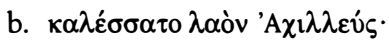
Achilles, he had the people called,

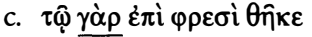
for on his mind she put [it],

modern literature on grammar and discourse (e.g., Hopper 1979: 215-I6) to treat digressive material in a story (marked by $\gamma \alpha \dot{\alpha} \rho$ in Greek) as explanatory background, as against the foreground of the main line of the narrative. The use of $\gamma \alpha$ ó $\rho$ in Homer runs counter to such a conception. See also Chapter 4 above.

51 Krischer 1971: 136-40. 


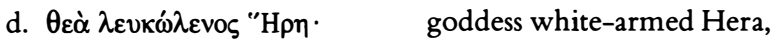

e. $\kappa \dot{\delta} \delta \varepsilon \tau 0 \underline{\gamma \alpha} \rho \Delta \alpha v \alpha \hat{\omega} v$,

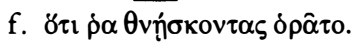

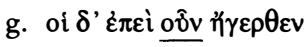

for she cared about the Danaans

since she saw [them] dying,

and they, when they were then assembled

(Il. I.54-57)

Again, we see a movement in three stages: starting point and orienting preview (units $\mathrm{a}-\mathrm{b}$ ), goal (unit $\mathrm{g}$ ), and movement from the one to the other (units $\mathrm{c}-\mathrm{f}$ ). The last-mentioned stage is not a twofold statement of a cause after its effect but reflects a deliberate strategy of moving from the global to the specific as a means of making headway in speech..$^{52}$ Notice, finally, that the particle oun (unit g) frequently signals the moment at which the goal is reached. This particle thus forms with gár a correlative pair ("goal sought ... goal reached"), a relation not unlike that between mén and dé in their processual, Homeric function. ${ }^{53}$

\section{Ring Composition and the Grammar of Discourse}

In the preceding discussion of addition and framing I aimed to show that adding style or parataxis in Homeric discourse is not just random cumulation. More often than not a unit is not only connected with what precedes but also leads to what follows, and this relation of any given present moment to its past and its future is what gives the listener an orientation and the discourse its meaning. But Homeric discourse would not be special speech if it did not systematize and enhance these strategies. Two aspects of the enhancement of framing and orientation concern us in the remainder of this chapter: the explicit articulation of orienting steps in ring composition, and their grammatical fixity in the case of the most frequently recurring scene in Iliadic narrative, the catalogic description of the epic androktasia, of which we have seen already some examples. Let us start with the latter case.

52 See also the $\gamma$ ó $\rho$ statements in Nestor's narrative (Il. I I.688, 690, 692, 698, 700). An extreme case is Hdt. 4.I.I-3, where we see no less than six statements with $\gamma \alpha \dot{\alpha} \rho$ in the buildup to the Scythian tale, all of which are regressive. See also Hes. Theog. 535 (first step in Prometheus story, cf. 52I and 6I5-I6), 57I (first step in Pandora story, cf. 570 and 585); WED 42, 43, 90 (marking the steps in the Pandora story, as indicated by Thalmann I984: 19).

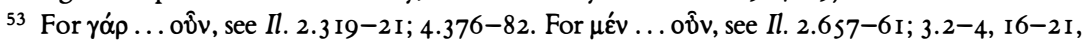
330-40. On oôv alone as coming to the narrative point, see Il. 3. I 54; 5.95; I0.272; I I.642; I6.394 (after a simile); 22.475; 24.329. The correlation of $\gamma \alpha \dot{\alpha} \rho$ and ov̂v is also common in post-Homeric Greek; see Van Ophuijsen (1993: 93-96) on Plato. 
In the preceding discussions we met a number of times with the scanning of a scene in the form of a three-stage process, consisting of a preview, a goal, and narrative space in between. This type of movement agrees with the tripartite structure that Charles Beye assigns as common property to the two most catalogic context types in Homeric discourse: the heroic androktasia in battle narrative and the entries in the Catalogue of Ships in the second book of the Iliad.$^{54}$ Beye observes that such catalogic progressions (which he calls items) typically consist of an A-part, giving the "basic information" (the names of the victor and the victim in the androktasia, or the name of the town and its leader(s) in the Catalogue); a B-part consisting of an "anecdote" (biographical or genealogical detail about the victim or the leader of the contingent); and a C-part, consisting of "contextual information" (detail that is relevant to the context of the list, that is, the actual fighting). ${ }^{55}$ The following passage is presented by Beye as a prime instance of what has become known as the $\mathrm{ABC}$-scheme:

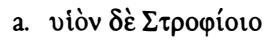
b. $\Sigma \kappa \alpha \mu \alpha ́ v \delta \rho t o v, \alpha i \mu o v \alpha \theta \dot{\eta} \rho \eta \varsigma$,

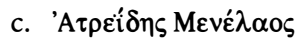

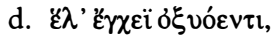

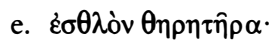

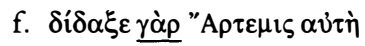

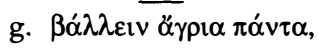

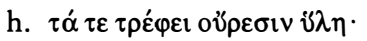

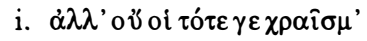

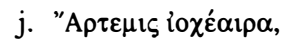

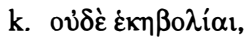

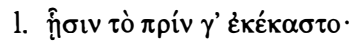

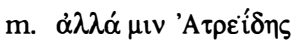

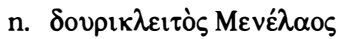
o. $\pi \rho o ́ \sigma \theta \varepsilon v \varepsilon \ddot{\varepsilon \varepsilon v} \varphi \varepsilon v ́ \gamma o v \tau \alpha$

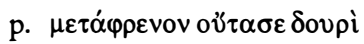

q. $\measuredangle \mu \omega v \mu \varepsilon \sigma \sigma \eta \gamma\langle\dot{s}$,

r. $\delta i \grave{\alpha} \delta \underline{\varepsilon} \sigma \tau \dot{\eta} \theta \varepsilon \sigma \varphi \imath v \dot{\varepsilon} \lambda \alpha \sigma \sigma \varepsilon v$,

s.

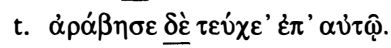

And the son (acc.) of Strophios,

Skamandrios skillful in the chase,

Atreus's son Menelaos (nom.),

he took [him] with the sharp spear,

the valiant hunter (=Skamandrios),

for Artemis herself had taught [him],

to strike at all the wild animals,

that the forest nourishes in the mountains;

but not then did she help him,

Artemis of the showering arrows,

nor did the far shootings,

in which earlier he excelled:

but him Atreus's son (nom.),

Menelaos famed for the spear,

[him] fleeing before him (=Menelaos),

he (=Menelaos) stabbed in the back with the

spear,

between the shoulders,

and he drove [it] through the chest,

and he fell forward on his face,

and his armor clattered upon him.

54 Beye I964; cf. Fenik 1968: I6-I7.

55 Beye 1964: 346-47. 
The basic information is given in units $\mathrm{a}-\mathrm{d}$; unit e provides a transition to the anecdote, which comprises units $\mathrm{f}-\mathrm{h}$; units $\mathrm{i}-\mathrm{l}$ provide a link between the anecdote and the contextual information, which runs from unit $\mathrm{m}$ to the end of the passage. ${ }^{56}$

To consider the androktasia as conforming to a structure that pertains to this particular narrative context or task might obscure the fact that what motivates the pattern is also common to the framing and orientation strategies discussed in the previous section. And to call this type of scene an item (as if it were a record in a database, consisting of three fields) might likewise obscure the dynamic nature of Homeric catalogues; for the management of this database remains a matter of movement, in which the narrator makes use of the same framing and movement techniques that we discussed earlier. In the example just presented, for example, the anecdote is introduced by the particle gár in unit $\mathrm{f}$, which, as often in Homer, signals the first step into the frame, toward the goal indicated. The frame, in this case, is set by unit e, esthlòn thêrêtêra 'valiant hunter', which leads up to units $\mathrm{o}-\mathrm{p}$ : the hunter has become hunted. ${ }^{57}$ The transition from the anecdote to the contextual information is made in unit $\mathrm{m}$ by the adversative particle allá 'but', which underlines the double irony of the protégé being abandoned by his divine patron in the hour of need, and of the warrior slain being the patient in an activity in which he himself excels.

In other cases it is not the particle gár but an appositional relative clause that introduces the anecdote, signaling movement into the frame; and instead of alla it is the relational demonstrative that marks the transition to the contextual information, or the moment previewed by the orientation;

a. $\tau \grave{\omega} \delta \grave{\varepsilon} \pi \varepsilon \sigma o ́ v \tau^{\prime} \varepsilon_{\lambda} \varepsilon_{\eta} \eta \sigma \varepsilon$

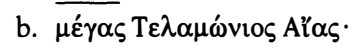

and the two falling he pitied,

huge Aias son of Telamon,

56 Units $\mathrm{p}-\mathrm{t}$ closely resemble the details of a killing described a few moments earlier in the narrative (5.40-42), a killing without an anecdote, in which $\gamma \alpha$ ó $\rho$ does not mark the step from $A$ to

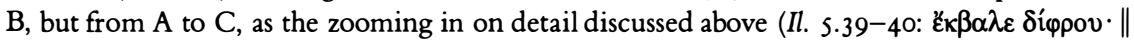

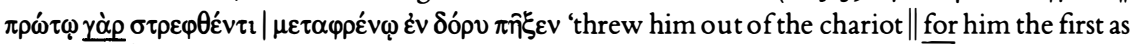
he turned $\mid$ he planted the spear in his back'). See also Beye 1964: 347; Visser 1987: 50. Other killings without a B-part, not mentioned by Beye, are the examples discussed above, in which the unit with the names of the victor and the victim can be seen as a condensed version of the A-part, and the unit with the verb as the C-part (Bakker I 990b: is n. 45). For a typology of killing-scenes, see Visser 1987: 44-57.

57 The killing occurs in the context of a major rout in the battle, in which victims are mounting their chariots in order to escape and are killed from behind. See such formulas as vú $\xi$ '

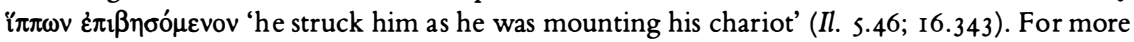
details see Latacz I977: 21 2-23. 


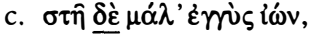

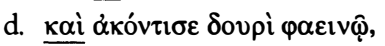

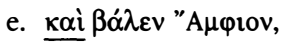
f. $\overline{\Sigma \varepsilon \lambda} \dot{\alpha} \gamma o v$ vióv,

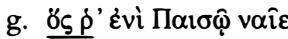
h. $\pi \mathrm{o} \lambda v \kappa \tau \eta \dot{\mu} \mu \omega v \pi \mathrm{o} \lambda v \lambda \eta \dot{i} \mathrm{o}$.

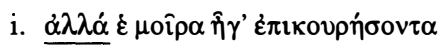

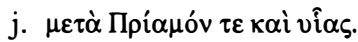

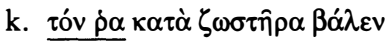

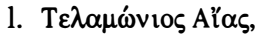

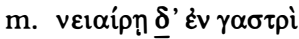

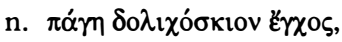

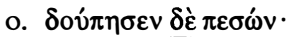
p. $\delta \delta$ ' $\varepsilon \pi \varepsilon \dot{\varepsilon} \delta \alpha \mu \varepsilon$
q. $\varphi \alpha i \delta$ inos Alas
r. $\tau \varepsilon \dot{\chi} \chi \varepsilon \alpha \sigma \nu \lambda \eta \dot{\sigma} \sigma \omega v$.

and he stood coming quite close in, and made a cast with the shining spear, and hit Amphios, the son of Selagos, who lived in Paisos, rich in possessions rich in harvest, but his fate brought him as an ally, for Priam and [his] sons, so him in the girdle he hit, Aias Telamon's son (nom.), and in the lower belly, it stuck, the far-shadowing spear and he fell with a thud, and he rushed forward, shining Aias, to strip the armor.

The A-part in this case (units $a-f$ ) is not the mere pairing of two names in order to frame a catalogic entry, but involves an appearance of Aias by way of a noun-epithet formula in unit $b$, in a typical way that will concern us in Chapters 7 and 8. What follows is an example of the throw-and-hit sequence discussed in Chapter 4 , involving the particle kaí, and revealing the name of the victim. The B-part (units $\mathrm{g}-\mathrm{j}$ ), which is introduced by an appositional relative clause, gives depth to the killing by situating it within the interrelated network of the heroic world and its inhabitants; far from being a digression containing detail that is not immediately relevant for the context at hand, it constitutes an important moment in the movement of epic discourse in more than one temporal dimension: the killing proper (the C-part, units $\mathrm{k}-\mathrm{r}$ ) can now take place within the context of the victim's tradition. ${ }^{58}$

58 This poetics of the androktasia, in which the kleos of the warrior slain serves as context for the kleos of the victorious hero, is grounded in the mentality and point of view of the epic heroes themselves. See the passage (Il. 7.8I-9I) in which Hektor imagines the $\sigma \hat{\eta} \mu \alpha$ 'tomb' of the warrior slain by him as what activates his own kleos in the minds and speech of men to come. Note, furthermore, that the appositional relative clause introducing the victim's tradition is

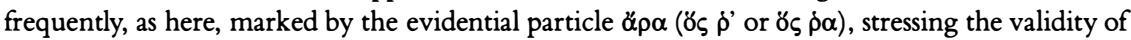
the present speech as based on previous speech. Likewise, the relational pronoun introducing the description of the killing proper is often marked by the same particle ( $\tau$ óv $\dot{\rho} \alpha$ ), emphasizing that the description is prompted by evidence produced by the present discourse itself; for more details, see Bakker 1993b: Is-23; 1997a. 
Rather than a fixed structure, then, to be inserted as a stereotyped item in a given context, the ABC-pattern is a case in which the usual presentation and orientation strategies of epic discourse are directed at a specific goal. And what structural fixity there is in the scheme derives from the recurrent nature of this goal, which may lead, as often in human linguistic behavior, to routinization. In fact, we might view the ABC-scheme as the kind of grammar that will be discussed in more detail below (see Chapter 8): it displays the regularity that results from the recurrence of a given situation, in this case the need to have one warrior killed by another. Yet just as with all manifestations of grammar in live speech, this is not regularity for its own sake: fixity in battle catalogues is the result of recurrence, rather than vice versa. ${ }^{59}$

The ABC-scheme is but one of the possible directions from which ring composition can be approached; other directions include epic regression, the proleptic mentioning of an event before it is due in the chronology of a narrative; the natural order of chiasmus or hysteron proteron; and in general the relation between a frame and a goal. The common denominator of these strategies is the reciprocal relation between units in a sequence. In a simple case, unit a serves as a frame for unit $b$. This moment of framing is actually an instance of reciprocity: when unit a frames unit $b$, this means that unit $b$ provides detail for unit $a$.

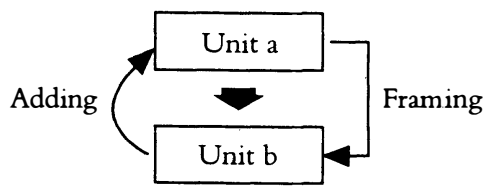

In more complex cases, the relationships and reciprocities are not merely confined to contiguous units.

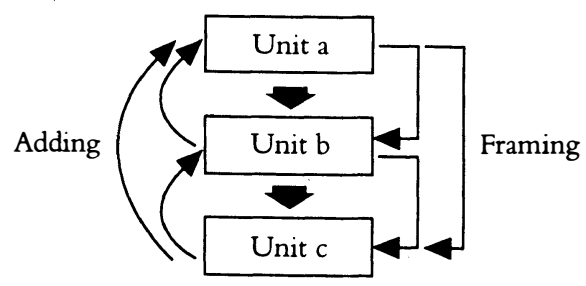

59 The criticism of the ABC-scheme in Tsagarakis 1982: 127-33 does not really apply, because fixity and regularity are a natural result of the use of the ABC-pattern as a recurrent discourse strategy (without implying either lack of freedom or formulaic necessity) rather than its purpose. 
Here the initial framing unit a (called the starting point in the discussions above) serves as frame for what is added to it (unit b), but at the same time looks ahead to what lies beyond (unit c). When this latter strategy is tightened and formalized by means of the devices mentioned above, or by similarities in phraseology between units a and c, we may speak of ring composition, which involves the explicit presentation of speech as uttered within a frame and the precise monitoring of the speech process by the speech itself. This is achieved by marking the end of the frame and indicating how a present moment relates to the past moment at which it was prepared.

Ring composition, then, is less a feature of archaic style as such (in opposition to other styles) than an index of the ways in which this style, as special speech, draws on the resources of ordinary speech. ${ }^{60}$ Yet the formalization is never so total that the ring becomes a structure for its own sake in which the end is a return to the beginning, a structure that finds its fulfillment in a symmetrical array on paper. ${ }^{61}$ The term "ring," in fact, might invoke the wrong image, in that speech, which proceeds through time, does not and cannot go back to an earlier point; it has to move forward and in so doing cannot but be uttered within the context of previous speech and provide context for speech to come. The principle that repetition in speech is impossible insofar as no two contexts are exactly identical appears to apply quite strongly in the case of ring composition: between the indication of the

60 The fullest account of ring composition is still Van Otterlo's, who makes the insightful suggestion (1944: 48) that ring composition is concerned, not so much with the repetition of the beginning as with the anticipation of the end, although he locates this observation in the climate characteristic of the time: "Auf diese Weise wurde ja in der früheren Periode der Stilgeschichte, da der menschliche Geist sich selbstverständlich noch nicht an längere Gedankenkomplexe gewohnt hatte, sowohl dem Autor für die Entfaltung der Gedanken, wie dem Publikum für das Verständnis derselben sof ort ein Anhaltspunkt gewährt." See also Gaisser 1969; Thalmann I984: 8-2I; Edwards I99I: 44-48. The present discussion is indebted to Lang I984: S-I2. For a discussion of hysteron proteron and chiasmus as figures of style related to ring composition, see Bassett 1938: I 20-25. Bassett rightly stresses the primacy of these phenomena as Homeric speech strategies over their status as recognized rhetorical figures in later times (on rhetoric and figures of style, see also Chapter 6 below). Minchin 1995, an approach congenial to my own, came to my attention too late to be of use in the preparation of this chapter.

${ }^{61}$ Note in this connection the difference between my use of framing and Thalmann's (1984) (whose emphasis on oral reception and the function of ring composition therein is otherwise consistent with my approach). Thalmann uses the term "framing" for the way in which a statement "surrounds" a given core. The term "ring composition," in fact, tends to be used by many scholars in a much wider sense than meant here, as any mirroring of segments on either side of a given center; the present discussion has focused on cases where such repetition can be more functionally accounted for in terms of starting points and goals. 
goal and its achievement, the world has changed. ${ }^{62}$ The global framingstatement, uttered during a moment of orientation, has become a specific, fully contextualized concept by the time the speaker reaches the goal.

The change is due, of course, to what lies between the two statements. Rather than a digression or an object inserted in the discourse, in-between speech is an integral part of its flow, approaching one of the salient moments of the discourse in a purposeful way. The section framed by the ringcomposition device is uttered to provide the context for what follows, enhancing the previewed moment (at the opening of the ring) by locating it within a temporal or conceptual perspective other than that which prevails at the moment of previewing. In the discussion of the $\mathrm{ABC}$-scheme we saw that the killing proper may be described within the context of the tradition of the victim, which lifts the narrative out of the time and place of the present moment. In other cases, such as similes (also a recurrent case of ring composition in Homer), the context provided is a realm of experience other than the one active at the present moment, but one that lends depth and significance to whatever is in the mind of the performer and the audience at the moment in question. ${ }^{63}$

Viewed in this light, the second mention of the previewed event is not so much the closing of the ring or the rounding off of a digression-and as such the transition of a backgrounded portion of the text back to the narrative foreground ${ }^{64}$-as a statement made in the reality produced by the discourse itself, a reality that has been explicitly established for the purpose of accommodating the previewed moment. In other words, the reciprocity between framing and adding (adding being the utterance of a unit or series of units within a frame) is nowhere more explicit than in the case of ring composition, a characteristic moment of Homeric discourse experienced as a flow of speech through time.

\section{Syntax and Suprasyntax: Some Conclusions}

In this chapter we have reviewed a number of phenomena in Homeric discourse that are likely to escape our notice within the perspective of

62 This point is repeatedly made by writers on ring composition. See Gaisser I969: 4; Thalmann 1984: 22.

63 See Edwards 1987: 102-10; I99 I: 24-4I.

64 On background and foreground, see Chapter 4. 
sentential syntax, but that are of importance for an understanding of how Homeric poetry is organized as a process. The discussion of framing has enabled us to establish a common denominator of phenomena that remain separate and disconnected in an approach less sensitive to the strategies specifically pertaining to the medium of speech. In particular, I have argued that some stylistic phenomena, such as chiasmus and ring composition, are not so much aesthetic features in their own right as natural consequences of the medium of speech as process.

Of central interest in this regard is the finding that one and the same phenomenon may be observed in various ways and in various degrees of grammatical fixity. We saw that Beye's ABC-pattern for killing-scenes and many ring-compositional phenomena are not so much schemes in their own right as tighter and more explicit versions of what happens elsewhere in a less structured way. In Chapter 8 we will study even tighter forms of the same phenomenon: framing and addition on the level of the verse in the metrical grammar of poetry. But we can also move to the opposite end of the scale: framing is not confined to syntax in the more narrow sense of the articulation of clauses and phrases at the local level. Syntax and suprasyntax, the grammar of the story as a whole, are manifestations at different levels of one and the same phenomenon. In other words, the goal indicated by a given framing speech unit, or series of units, may be farther ahead than in the examples discussed; yet the strategy of moving from the one to the other is not different from the syntax of framing that we have studied. ${ }^{65}$

In this way the Iliad begins with a preview. Not only the first speech unit of the Iliad, but also the proem and indeed the whole first book, look ahead to the moment at which the action of the wrath of Achilles really takes off, much later in the poem. This much lauded quality of in medias res, however, appears much less the virtue by which a poem and its poet can be distinguished from other poems and their authors-Homer having emancipated himself from the paratactic composition style and compulsory sequentiality of his forebears - than an effective way of drawing on the specific properties of the spoken medium. No speech is meaningful out of context, and in framing the narrative, locally as well as globally, the epic narrator opens up narrative space, provides direction, and intensifies the experience of those who move along the path by creating anticipation of what lies ahead.

65 See Lang 1984: 7-8, on "hooks"; Thornton 1984: 67-72, on "goals" and "signposting"; Thalmann 1984: I3-I4, on the proleptic introduction of the Cyclopes and Hundred-handers in Hes. Theog. $139-53$. 